With regard to the treatment of the mentally afflicted, I think that before being certified a patient should be treated, and not sent to an asylum unless he is a bad case. It is terrible to send a young person to wake up in a lunatic asylum, to be branded for life for that which is often the fault of others, or a mere nervous disturbance which may be all over in ten days. That in itself is enough to cause a permanent deterioration of the brain. There should be certainly a half-way house between the asylum and a patient's own home.

In a letter to the Nursing Mirror last October I highly praised the mental nurse. I think, however, that she makes mistakes which could be remedied. With but a little effort of the imagination, she could place herself in her patient's place, and feel as he feels-lonely, terrified, weak, ashamed of his weakness, humiliated by the memory of his breakdown and the shock that it caused to others. She could soothe and cheer, be silent in the corridors at night-not leave him alone in the cold and dark, to get well or to get worse, or to die.

Suggestion, experiment or psycho-analysis is absolutely and obviously pernicious, for the mind is sick and defenceless, and too weak to be able to resist by reason, or right instinct.

A mental patient lacks will-power and self-confidence, and is bitterly ashamed of himself for being the reverse of what he was before. He is full of conflict, and cannot give plain and straightforward answers. His civilized nature is at war with his primitive instinct - especially is this so in the case of women, who often have or choose to repress many of their own wishes and ambitions.

Symbolism, too, plays a large part in the mental life of the patient, and many cultured and reserved people, when they are insane, say and do things which only a cultured and able attendant would understand. Food may, to a patient, represent life, or money ; and it is not always easy to tell what a patient means ; but once the symbolism is grasped by the mental expert, he will be able to reassure the patient, and change the current of his thoughts. In any case, he is bound to be morbid and very hypersensitive. Feeling inferior, he may develop a complex by which the instinct of self-preservation may, for example, be perverted temporarily, and so on.

The subject is, of course, one of vast interest ; and as I stated here before, I have seen no cruelty in an asylum, save the legal one which denies a patient a chance to see or write to a friend, and leaves him at the mercy of one petitioner -usually the relative who rushed to have him put away, and who may be a stranger to the patient in everything but blood. I have had happy days in an asylum, and I think the world of my nurses, all of whom respected my reserves, and showed a human rather than professional interest in me, and who showed all their patients the respect and devotion due to the sick. And it is only this human interest which will obtain the response of a patient, for very often the "clever" nurse will make erroneous deductions from sick symptoms, since pathology is a very intricate subject indeed-even to the expert pathologist.

At least, I hope that he thinks so.

J. S. C.

\title{
THE TREATMENT OF RATE-AIDED PATIENTS AS VOLUNTARIES IN
} THE MENTAL HOSPITALS OF SCOTLAND.

THE following extracts from a memorial addressed to the Secretary of State for Scotland by the Board of Direction of the Crichton Royal Institution are of importance and general interest :

"The Institution is the only mental hospital in the country which publishes annual statistics of the results of treatment of the voluntaries, for purposes of comparison with those relating to the certificated patients, and this fact, and the foregoing data, as to the size and nature of its population, indicate that the Institution is specially in a position to furnish pertinent and important statistical information not otherwise available.

"The following tabular statement shows the results of treatment at the Institution for the 17 years 1908 to 1924 inclusive. (N.B. - The cases admitted and the cases discharged improved or unimproved include transfers respectively from and to other mental hospitals) :

LXXI. 


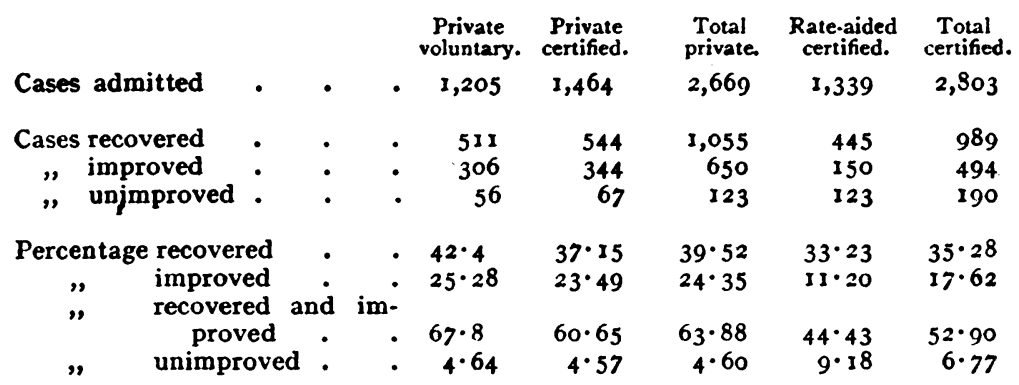

"It will be seen that the results of treatment are best among the private voluntary, less favourable among the private certificated, and worst among the rateaided certificated group. As regards the private class, the results are better among the voluntary than among the certificated, for the reason that the former exhibit in larger proportion illnesses of less serious type and more recent duration. As regards the difference in the results of treatment among the private as compared with the rate-aided class, the significance of the figures will be realized more fully when it is stated that the rate-aided patients were sent direct from their homes in nearly all cases, and were treated under the same hospital conditions and arrangements as the private patients, whereas the great majority of the latter had been treated previously in nursing homes and private houses. There is good reason to believe-and this is an important point to remember in considering the statistics of treatment in mental hospitals-that it is the worse half of the nervous breakdowns in the community that have to be dealt with in mental hospitals. This certainly applies to private patients, and also to rate-aided patients in those asylums which serve populous centres provided with separate mental or observation wards. It is recognized that the more favourable results of mental hospital treatment among private as compared with city rate-aided patients may be accounted for to some extent by the difference in the previous mode of life and social environment of the two classes. This consideration is hardly applicable to the rate-aided patients from the healthy rural area of Dumfriesshire and Galloway, amongst whom, for the reasons above stated, it might have been expected that the results of treatment would have been even better than among the private class. As the above figures show, the contrary is the case. In order to visualize the desirable results that might ensue if rate-aided patients were permitted to come for treatment of their own accord to mental hospitals, the figures for the private voluntary should be compared with those for the rate-aided certificated group. The recovery rate (or number discharged as recovered per 100 admitted) of the former exceeded that of the latter by 9.2 per cent. If there also be taken the figures for those discharged as improved, thereby including all who were restored in health, and in the great majority of cases to fitness for home life and efficiency for work, the proportion of recovered plus improved among the private voluntary group exceeded that for the rate-aided certificated by 23.3 per cert. It is reasonable to surmise that if rate-aided patients were afforded suitable facilities for entering public mental hospitals as voluntaries, they would come as readily as patients of the private class, and with a prospect of equally good therapeutic results. The conservative estimate of a ro to 15 per cent. improvement in the results of their treatinent is obviously worthy of serious consideration, not only from the humanitarian aspect, but also from the point of view of the national welfare.

" Rate-aided patients can be legally admitted for treatment as voluntaries in Scottish asylums, but notwithstanding that this has been possible for nearly sixty years, the extreme rarity of a rate-aided voluntary in a Scottish asylum in the past is proof in itself that such provision as exists has hitherto been practically a dead letter. In actual practice the patient has to wait until he is ill enough to be certified as a 'lunatic,' thus losing the opportunity of systematic early treatment in a hospital specially equipped for the purpose; yet in no group of diseases is early treatment more important than in the case of mental disorders, owing to the extreme delicacy of structure of that organ which represents the supreme achievement in the scale of evolution, the human brain. Further, in order to 
become a 'lunatic' for purposes of treatment, the patient also has to become a 'pauper' on the 'poor roll' of the parish, the procedure for certification and admission being under the control of the poor law authority, which is responsible for action, and also liable (in part) for the patient's maintenance. The majority of self-respecting men and women shrink from the shame of applying to the parish, as also from the odium of certification. Hence valuable time is lost in many cases; and such feelings are not conducive towards recovery when mental hospital treatment eventually becomes an urgent necessity, and further, they are apt to be attached to the hospital itself, and to the 'lunacy' system generally.

"In accordance with existing legislative enactments in Scotland, the maintenance of 'pauper lunatics' in the asylums, poorhouses and private dwellings is paid for mainly out of the rates imposed by the local authorities (District Boards of Control and Parish Councils), also out of the lunacy grant from the local taxation account, and by contributions from relatives and others. It is important to note that the lunacy grant is paid to the Parish Councils, and towards the cost of 'pauper lunatics' only, and that, according to the latest, or Tenth, Annual Report of the General Board of Control for Scotland, the lunacy grant for the year ended 15th May, 1923, amounted to $f 115,703$, or about $2 s$. $9 d$. weekly for each certified patient. It is to be observed that there is no statutory provision for the application of the grant towards the cost of voluntary patients of the rate-aided class, and this has proved the great obstacle in the past to the admission of rate-aided patients as voluntaries to the public asylums. Parish Councils have been reluctant to lose the benefit of the grant (as they would do) in the case of voluntary rate-aided patients in asylums, and consequently they have not encouraged the voluntary system. This short-sighted policy would soon be discarded by a simple and obvious provision of the statute, one of the effects of which would be to reduce the disability of certification-in the apt words of the above Report-' to its proper place of a social and legal necessity.' The disability of pauperization could not be removed unless the present lunacy obligations of the Parish Councils of the country were transferred by appropriate legislation to the District Boards of Control, thereby bringing the administration of mental diseases into line with that of infectious diseases, including tuberculosis.

"It seems only fair to expect, if the above disabilities were remedied and the early treatment of mental diseases was encouraged in the ways indicated, that rate-supported mental patients would in time come to the mental hospitals at least as willingly as do private patients at present, and perhaps eventually with no more reluctance than do the rate-aided inmates of fever hospitals and sanatoria.

"In any case, the legislation which the Board of the Crichton Royal Institution now so earnestly urges and recommends would not only remedy factors which at present seriously handicap the mental hospital treatment of the rate-aided or poorer classes, but also by facilitating their early treatment, as voluntary inmates of mental hospitals, would do much to enhance the utility of the statutes, and effectually promote the general health, happiness and efficiency of the community. "W. J. H. MAXWELL,

Chairman of the Board of Direction.

“C. C. EASTERBROOK,

Physician Superintendent of the Institution."

OBITUARY.

Williay ArNot Parker, M.B., C.M.Glasg.,

Medical Superintendent, Glasgow District Mental Hospital, Gartloch, N.B.

We regret to announce the death of Dr. William Arnot Parker, who died at his residence, Beechwood, Gartloch, on Wednesday, December 24 .

Though he had been failing in health for some years, his wide circle of friends and acquaintances were hopeful that he had recently regained his strength and had still before him years for useful work, but the end came suddenly and unexpectedly.

Dr. Parker graduated in 1889 at Glasgow University, and after an experience in general hospital work was for several years Assistant Medical Officer in the County Asylum at Lancaster and the Glasgow Royal Asylum, and Senior Assistant at Gartloch Asylum. 